\title{
USE OF THE CAPNOMETRY AS A RENAL GRAFT EVOLUTION PREDICTOR IN UNCONTROLLED CARDIAC ARREST DEATH DONORS
}

Alicia Villar-Arias ${ }^{1}$, Alonso Mateos-Rodríguez ${ }^{2}$, Carlos Rubio-Chacón ${ }^{1}$, Esther González ${ }^{3}$, Natalia Polanco ${ }^{3}$, Eduardo Gutiérrez ${ }^{3}$, Amado Andrés-Belmonte ${ }^{1}$ Emergency Department SUMMA 112, Community of Madrid Health Department, Madrid, Spain; ${ }^{2}$ Community of Madrid Regional Transplants Office, Community of Madrid Health Department, Madrid, Spain; ${ }^{3}$ Nephrology Department, Doce de Octubre University Hospital, Madrid, Spain

Introduction: The modified Maastricht classification identifies type lla donors as uncontrolled donors after cardiac death and includes those patients who do not recover spontaneous circulation after advanced life support. Capnometry or end-tidal carbon dioxide (Et-CO2) is clearly related to ventilation and tissue perfusion.
Objective: To correlate the levels of capnometry during resuscitation and preservation process with the viability and evolution of renal grafts. Therefore, the EtCO2 may be a parameter to be assessed in the suitability of grafts from uDCD.

Methodology: Retrospective descriptive study from 2013 to 2017 based on the data collection from a series of potential donors transferred by SUMMA112 to Doce de Octubre University Hospital and the post-transplant evolution.

\section{Results:}

\begin{tabular}{|c|c|c|c|}
\hline & $\begin{array}{l}\text { Grafted kidney } \\
\qquad(n=30)\end{array}$ & $\begin{array}{c}\text { No grafted } \\
\text { kidney } \\
(n=7)\end{array}$ & P-value \\
\hline Age (years) & 45,83 & 40,43 & $p=0,051$ \\
\hline Gender (male/female) & $26 / 4$ & $7 / 0$ & $p=0,306$ \\
\hline Initial capnometry (mmHg) & 26,6 & 21,57 & $p=0,471$ \\
\hline Transfer capnometry (mmHg) & 22,8 & 17,35 & $p=0,016$ \\
\hline Smoker (\%) & 40 & 42,85 & $p=0,890$ \\
\hline $\begin{array}{l}\text { Time Cardiac Arrest- Advanced life } \\
\text { support (min) }\end{array}$ & 12,6 & 9,43 & $p=0,119$ \\
\hline Normothermic perfusion (hours) & 5,61 & 5,41 & $p=0,487$ \\
\hline
\end{tabular}

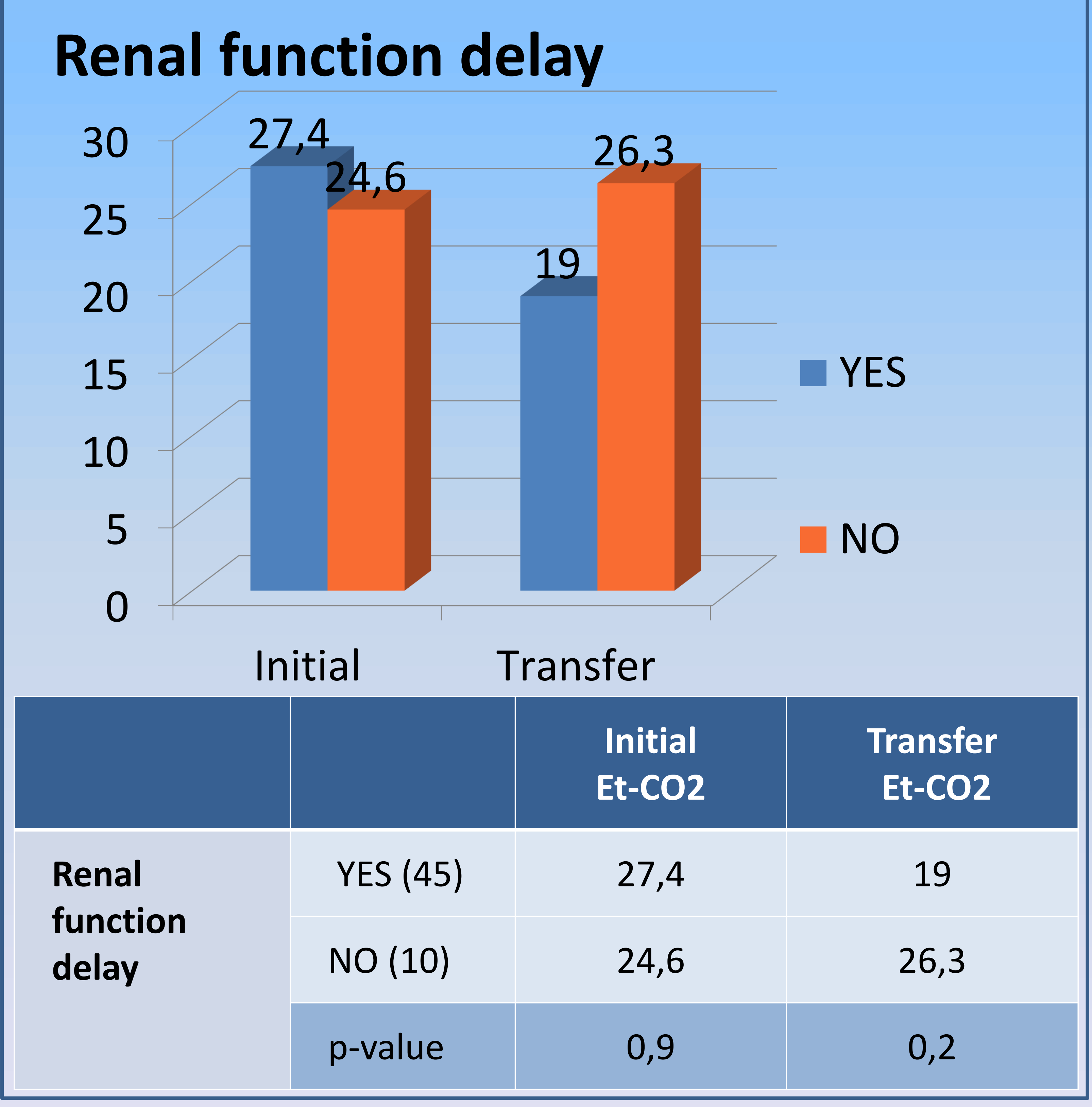

\begin{tabular}{|c|c|c|}
\hline & $\begin{array}{c}\text { Et-CO2 } \\
(\text { SD) }\end{array}$ & p Value \\
\hline Grafted & 22,80 & \\
kidney & $( \pm 9,412)$ & $p=0,016$ \\
\hline No grafted & 17,35 & \\
kidney & $( \pm 10,323)$ & \\
\hline
\end{tabular}

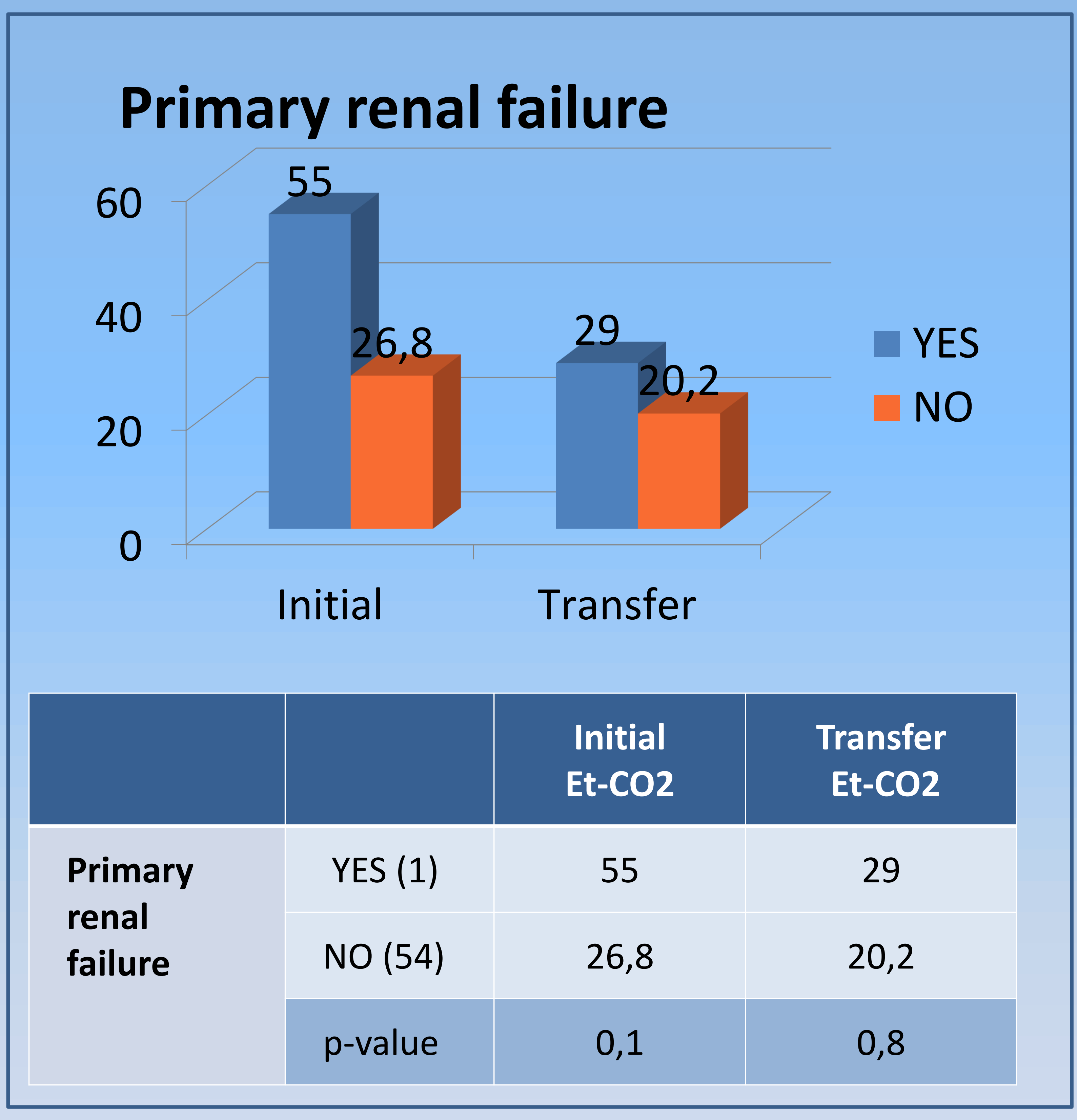

No patient has presented an acute graft rejection

Graft survival was $100 \%$

No death occurred during the study period

\section{Conclusions:}

A statistically significant association has been found between the capnometry values and the validity of the renal grafts

It seems that there is an association between lower capnometry values with a delay in renal function of graft, although without statistical significance. This may be influenced by the sample size.

A prospective study that analyzes the validity of the capnometry as a predictor of the organs suitability in the uDCD in more depth is needed. 